\title{
Co-production of acetoin and succinic acid by metabolically engineered Enterobacter cloacae
}

Hsiang-Yen Su ${ }^{1,2,3}$, Hua-Ying Li ${ }^{3}$, Cai-Yun Xie ${ }^{3}$, Qiang Fei ${ }^{2^{*}}$ and Ke-Ke Cheng ${ }^{1,3^{*}}$

\begin{abstract}
Background: Renewable chemicals have attracted attention due to increasing interest in environmental concerns and resource utilization. Biobased production of industrial compounds from nonfood biomass has become increasingly important as a sustainable replacement for traditional petroleum-based production processes depending on fossil resources. Therefore, we engineered an Enterobacter cloacae budC and IdhA double-deletion strain (namely, $\mathrm{E} C \triangle \mathrm{bud}(\triangle \mathrm{IdhA}$ ) to redirect carbon fluxes and optimized the culture conditions to co-produce succinic acid and acetoin.

Results: In this work, E. cloacae was metabolically engineered to enhance its combined succinic acid and acetoin production during fermentation. Strain $\mathrm{EC} \triangle \mathrm{budC} \triangle \mathrm{ldhA}$ was constructed by deleting 2,3-butanediol dehydrogenase (budC), which is involved in 2,3-butanediol production, and lactate dehydrogenase (IdhA), which is involved in lactic acid production, from the E. cloacae genome. After redirecting and fine-tuning the E. cloacae metabolic flux, succinic acid and acetoin production was enhanced, and the combined production titers of acetoin and succinic acid from glucose were 17.75 and $2.75 \mathrm{~g} \mathrm{~L}^{-1}$, respectively. Moreover, to further improve acetoin and succinic acid production, glucose and $\mathrm{NaHCO}_{3}$ modes and times of feeding were optimized during fermentation of the $\mathrm{EC} \triangle \mathrm{budC} \Delta \mathrm{ldhA}$ strain. The maximum titers of acetoin and succinic acid were 39.5 and $20.3 \mathrm{~g} \mathrm{~L}^{-1}$ at $72 \mathrm{~h}$, respectively.

Conclusions: The engineered strain EC $\triangle$ budC $\triangle \mathrm{ldhA}$ is useful for the co-production of acetoin and succinic acid and for reducing microbial fermentation costs by combining processes into a single step.
\end{abstract}

Keywords: Enterobacter cloacae, Metabolic engineering, Co-production, Acetoin, Succinic acid

\section{Background}

Renewable chemicals have attracted attention due to increasing interest in environmental concerns and resource utilization. Biobased production of industrial compounds from nonfood biomass has become increasingly important as a sustainable replacement

\footnotetext{
*Correspondence: feiqiang@xjtu.edu.cn; chengkeke@dgut.edu.cn 1 Engineering Research Center of Health Food Design \& Nutrition Regulation, School of Chemical Engineering and Energy Technology, Dongguan University of Technology, Dongguan 523808, China

${ }^{2}$ School of Chemical Engineering and Technology, Xi'an Jiaotong University, Xi'an 710049, China

Full list of author information is available at the end of the article
}

for traditional petroleum-based production processes depending on fossil resources. Both acetoin and succinic acid are $\mathrm{C} 4$ chemicals that listed biobased highvalue-added chemicals by the United States Department of Energy [1]. Currently, acetoin and succinic acid are building block chemicals used extensively in the food and pharmaceutical industries.

Acetoin is a volatile compound that occurs naturally in certain fruits and dairy products. Commercial acetoin can be used as a plant growth promoter, biological pest control measure, and additive to improve food flavor [2, 3]. At present, acetoin is produced mainly by chemical synthetic routes. Compared with chemical 
synthesis methods, microbial fermentation methods have the advantages of easy access to feedstock, environmental friendliness and mild process conditions [4, 5]. Therefore, microbial fermentation is considered to be an environmentally friendly method for the production of acetoin, which has made great progress in recent years. Many microorganisms synthesize acetoin during the mixed acid fermentation process, such as Enterobacter, Klebsiella, Lactococcus, Bacillus, Serratia and Saccharomyces species [6]. Acetoin is an intermediate product of the 2,3-butanediol biosynthesis pathway [7]. It is produced from pyruvate through $\alpha$-acetolactate by two enzymes, including $\alpha$-acetolactate synthase $(b u d B)$ and $\alpha$-acetolactate decarboxylase $(b u d A)$, and finally converted to 2,3-butanediol by 2,3-butanediol dehydrogenase (budC) with the consumption of NADH [8]. Several studies have reported that the deletion of 2,3-butanediol dehydrogenase $(\mathrm{budC})$ improves the production of acetoin in different species of microorganisms $[2,3,9,10]$.

In a traditional acetoin fermentation process, succinic acid is an undesirable by-product. However, succinic acid, a C4 dicarboxylic acid, has been used as a precursor for various chemicals, ion chelators, and additives in the food and pharmaceutical industries [11]. In addition, succinic acid can be converted into other chemicals, such as $\gamma$-butyrolactone, 1,4-butanediol, and tetrahydrofuran, and act as the precursor of polybutylene succinate synthesis. In E. coli, the reductive branch of the tricarboxylic acid (TCA) pathway function is the key pathway for the synthesis of succinic acid. The carboxylation of phosphoenolpyruvate (PEP) to oxaloacetate (OAA) catalyzed by PEP carboxylase (PEPC) is considered the most important reaction. In this step, $1 \mathrm{~mol} \mathrm{CO}_{2}$ is assimilated to form OAA [2]. Therefore, $\mathrm{CO}_{2}$ is an essential substrate for succinic acid biosynthesis, and it has been demonstrated that the production of succinic acid can be increased by sodium bicarbonate $\left(\mathrm{NaHCO}_{3}\right)$ addition to the culture medium [12, 13]. Additionally, when grown under anaerobic conditions, E. coli metabolizes phosphoenolpyruvate (PEP) and pyruvate via the glycolytic pathway to form ethanol, lactic acid, and formic acid [14]. Therefore, changing the carbon flux towards the synthesis of succinic acid by metabolic engineering is very important [15]. Currently, numerous industrially used microorganisms have been metabolically engineered for succinic acid production by fermentation [16-19].

An earlier study revealed that E. cloacae can produce $40.67 \mathrm{~g} \mathrm{~L}^{-1} 2$,3-butanediol and $21.79 \mathrm{~g} \mathrm{~L}^{-1}$ succinic acid from xylose [20]. In this study, to redirect the carbon flux, a double-deletion mutant (strain EC $\Delta$ budC $\Delta$ ldhA) of E. cloacae was developed by deleting 2,3-butanediol dehydrogenase $(\mathrm{budC})$ to produce acetoin and by deleting lactate dehydrogenase (ldhA) to improve succinic acid production (Fig. 1). Moreover, the feeding mode and time of glucose and $\mathrm{NaHCO}_{3}$ during the fermentation of the EC $\Delta$ budC $\Delta$ ldhA strain were optimized, which further enhanced the production of acetoin and succinic acid. The present findings demonstrated a potential practical strategy for the simultaneous production of two commercial products in a single fermentation step by redirecting the carbon flux and optimizing the culture conditions.

\section{Results}

\section{Construction of the metabolically engineered strains}

Enterobacter cloacae has an extraordinary ability to utilize biomass for 2,3-butanediol production, during which intermediary acetoin is formed [10]. Acetoin reductases (also known as 2,3-butanediol dehydrogenase) catalyze the transformation reaction from acetoin to 2,3-butanediol. Knockout of the $b u d C$ gene would generate the EC $\Delta$ budC strain, which mainly produces acetoin. A previous study showed that reducing the carbon flux to lactate, ethanol, and acetate by-products can be performed by deleting the $l d h A, a d h E$, and pta genes in K. pneumoniae [7]. In this study, to further reduce lactic acid production in the fermentation process, the $\operatorname{ldh} A$ gene was disrupted from the wild type and EC $\triangle$ budC strains to generate strains $\mathrm{EC} \Delta \mathrm{ldh} \mathrm{A}$ and $\mathrm{EC} \Delta \mathrm{budC} \Delta \mathrm{ldh} \mathrm{A}$, respectively. The budC and $l d h A$ gene knockout of these strains was verified by screening with colony PCR (data not shown).

To determine the effects of deleting budC and $l d h A$ on cell growth, wild type and three deletion mutants, $\mathrm{EC} \Delta$ budC, EC $\Delta \mathrm{ldhA}$, and $\mathrm{EC} \Delta$ budC $\Delta \mathrm{ldhA}$, were grown under $60 \mathrm{~g} \mathrm{~L}^{-1}$ glucose and $5 \mathrm{~g} \mathrm{~L}^{-1} \mathrm{NaHCO}_{3}$ at $35^{\circ} \mathrm{C}$ at $150 \mathrm{rpm}$, followed by comparison of the growth curves. The initial inoculum of these cultures was the same $\left(\mathrm{OD}_{600}=0.15\right)$. The growth results are shown in Fig. 2 . The EC $\Delta$ budC and EC $\Delta$ budC $\Delta$ ldhA strains grew slower than the wild type in the first $12 \mathrm{~h}$. The $\mathrm{OD}_{600}$ values were 5.62, 4.58, and 4.54 for the wild type, EC $\Delta$ budC, and EC $\triangle$ budC $\Delta$ ldhA strains, respectively, after $24 \mathrm{~h}$ (Fig. 2). The growth rates of the EC $\Delta$ budC and EC $\Delta$ budC $\Delta$ ldhA strains were reduced by $22.7 \%$ and $23.7 \%$, respectively, in comparison with the wild type. In contrast, compared with the wild type, the EC $\Delta$ ldhA strain exhibited increased cell growth. The $\mathrm{OD}_{600}$ value was 5.77 for the ECAldhA strain (Fig. 2a). The glucose concentration in the medium of wild type and ECAldhA strains was depleted after $24 \mathrm{~h}$ of fermentation. The glucose concentrations of EC $\Delta$ budC and EC $\Delta$ budC $\Delta$ ldhA were depleted at $36 \mathrm{~h}$ (Fig. 2b). Jang et al. [9] reported that deletion of budC resulted in reduced cell growth and glucose consumption rate in Enterobacter aerogenes. These 


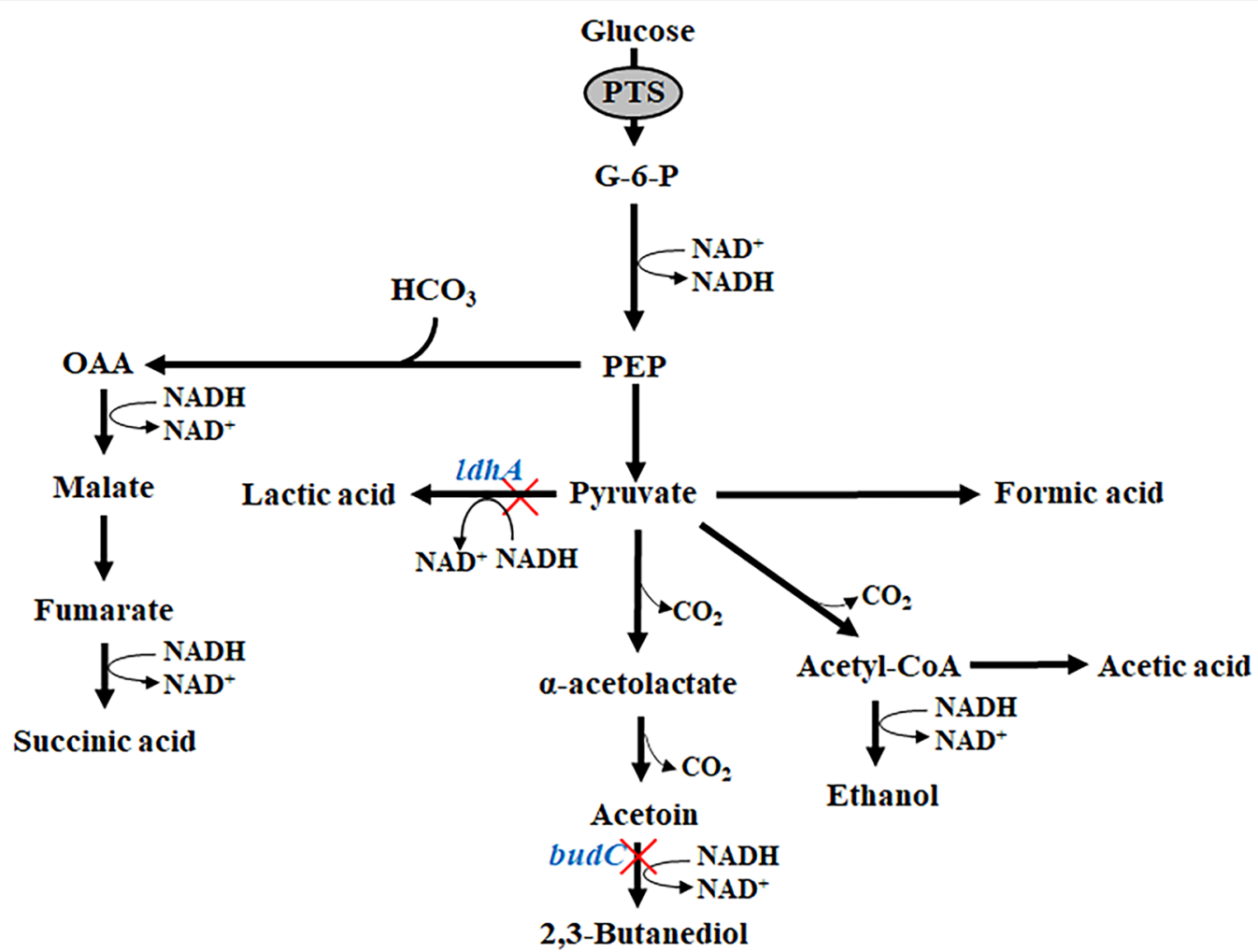

Fig. 1 Schematic representation of improved production of acetoin and succinic acid by deletion of budC and IdhA in E. cloacae
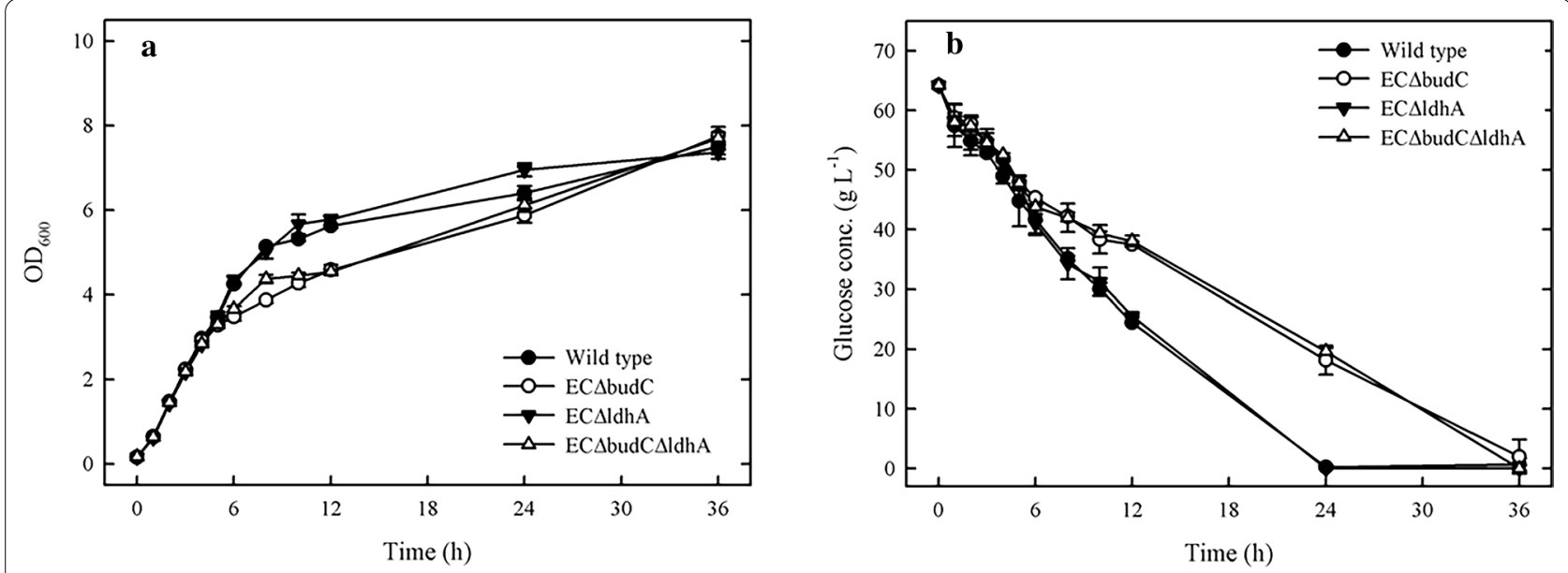

Fig. 2 Effects of knockout budC and IdhA on cell growth and consumed glucose of E. cloacae. The experiments were conducted in $50 \mathrm{~mL}$ of fermentation medium containing $60 \mathrm{~g} \mathrm{~L}^{-1}$ glucose and $5.0 \mathrm{~g} \mathrm{~L}^{-1} \mathrm{NaHCO}_{3}$ in a $250 \mathrm{~mL}$ flask at $35^{\circ} \mathrm{C}$ with shaking (150 rpm)

results indicated that deletion of the budC gene in $E$. cloacae cells might reduce the growth rate and glucose consumption.
Effects of metabolic engineering on enhanced co-production of acetoin and succinic acid

The wild type and EC $\Delta$ budC strains were grown at $35^{\circ} \mathrm{C}$ in $250 \mathrm{~mL}$ shake flasks containing $50 \mathrm{~mL}$ of fermentation medium supplemented with $90.0 \mathrm{~g} \mathrm{~L}^{-1}$ glucose and $5.0 \mathrm{~g} \mathrm{~L}^{-1} \mathrm{NaHCO}_{3}$. The fermentation was finished when 
glucose was consumed nearly completely. As shown in Table 1, EC $\Delta$ budC produced various organic acids and ethanol, with acetoin being a major product that accumulated to $18.6 \mathrm{~g} \mathrm{~L}^{-1}$, resulting in a 0.419 yield $\left(\mathrm{mol} \mathrm{mol}^{-1}\right.$ glucose). The concentrations of succinic acid, 2,3-butanediol, lactic acid, acetic acid and ethanol were 1.05, 7.7, 2.6, 2.75, and $4.75 \mathrm{~g} \mathrm{~L}^{-1}$, respectively. The succinic acid content of the EC $\Delta$ budC strain was decreased by 2.24 fold in comparison with that of the wild type strain. Succinic acid was measured as 2.35 and 1.05 for the wild type and $\mathrm{EC} \Delta$ budC strains, respectively. Lactic acid formation was not detected in the wild type strain. However, the lactic acid content of EC $\Delta$ budC $\left(2.6 \mathrm{~g} \mathrm{~L}^{-1}\right)$ was increased compared with that of the control and wild type (not detected).

D-Lactate dehydrogenase (encoded by $l d h A$ ) catalyzes the conversion of pyruvate to D-lactic acid by coupling with the oxidation of NADH in E. cloacae [21]. In this study, to reduce lactic acid production in the fermentation process, the $l d h A$ gene was inactivated in the wild type. The results indicated that the fermentation products of the ECAldhA strain were similar to those of the wild type (Table 1). The difference is that the succinic acid content of the EC $\Delta$ ldhA strain was increased by $19 \%$ in comparison with that of the wild type.

To achieve a higher yield of acetoin and succinic acid co-production, the EC $\Delta$ budC $\triangle$ ldhA strain was constructed by knocking out $l d h A$ genes in strain EC $\Delta$ budC. EC $\triangle$ budC $\triangle$ ldhA produced various organic acids and ethanol, with acetoin being a major product that accumulated to $17.75 \mathrm{~g} \mathrm{~L}^{-1}$, resulting in a yield of 0.397 (mol mol ${ }^{-1}$ glucose). The concentrations of succinic acid, 2,3-butanediol, acetic acid and ethanol were 2.75,
8.15, 1.4, and $5.05 \mathrm{~g} \mathrm{~L}^{-1}$, respectively. Lactic acid was not observed in the EC $\triangle$ budC $\triangle$ ldhA strain. The succinic acid content of the EC $\Delta$ budC $\Delta$ ldhA strain was increased by 2.24-fold in comparison with that of the EC $\Delta$ budC strain. The final concentrations of succinic acid were measured as 1.05 and $2.75 \mathrm{~g} \mathrm{~L}^{-1}$ for the EC $\triangle$ budC and EC $\triangle$ budC $\Delta$ ldhA strains, respectively. The succinic acid yield was measured as 0.046 and $0.018\left(\mathrm{~mol} \mathrm{~mol}^{-1}\right.$ glucose) for the EC $\Delta$ budC $\Delta$ ldhA and EC $\Delta$ budC strains, respectively.

The results indicated that elimination of 2,3-butanediol and lactic acid formation in the EC $\Delta$ budC $\Delta$ ldhA strain led to enhanced acetoin and succinic acid co-production, and the maximum acetoin and succinic acid yields were obtained as 0.397 and $0.046 \mathrm{~mol} \mathrm{~mol}^{-1}$ glucose, respectively.

\section{Effect of $\mathrm{NaHCO}_{3}$ concentration on metabolite production by the EC $\Delta$ budC $\Delta$ ldhA strain}

Previous studies have shown that $\mathrm{CO}_{2}$ is a key parameter in batch succinic acid fermentation. The amount of dissolved $\mathrm{CO}_{2}$ can be increased effectively by the addition of $\mathrm{NaHCO}_{3}$ to the medium [20]. To compare the effects of $\mathrm{NaHCO}_{3}$ levels, different concentrations of $\mathrm{NaHCO}_{3}$ $\left(0,2.5,5,7.5\right.$, and $\left.10 \mathrm{~g} \mathrm{~L}^{-1}\right)$ were added to the fermentation medium. As shown in Table 2, when grown in fermentation medium without $\mathrm{NaHCO}_{3}$, the final production of acetoin after $24 \mathrm{~h}$ was $16.45 \mathrm{~g} \mathrm{~L}^{-1}$. The concentrations of succinic acid, 2,3-butanediol and ethanol were $1.15,3$, and $6.25 \mathrm{~g} \mathrm{~L}^{-1}$, respectively. However, a higher concentration of $\mathrm{NaHCO}_{3}$ led to a negative effect on acetoin production. The concentration of acetoin was decreased by $7,19,10.6$, and $24.6 \%$ for $2.5,5,7.5$, and

Table 1 Fermentation profiles of the gene knockout strains of E. cloacae

\begin{tabular}{|c|c|c|c|c|}
\hline Strain & WT & $\Delta$ budC & $\Delta \mathrm{ldhA}$ & $\Delta$ budC $\Delta \mathrm{ldh} A$ \\
\hline Final pH & $5.92 \pm 0.007$ & $6.08 \pm 0.071$ & $6.09 \pm 0.0035$ & $5.9 \pm 0.028$ \\
\hline Consumed glucose $\left(\mathrm{g} \mathrm{L}^{-1}\right)$ & $92.2 \pm 0$ & $90.8 \pm 0$ & $92.7 \pm 0$ & $91.4 \pm 4.34$ \\
\hline Final $O_{600}$ & $8.92 \pm 0.057$ & $7.83 \pm 0.028$ & $9.345 \pm 0.274$ & $8.245 \pm 0.12$ \\
\hline Final succinic acid $\left(\mathrm{g} \mathrm{L}^{-1}\right)$ & $2.35 \pm 0.071$ & $1.05 \pm 0.071$ & $2.8 \pm 0.141$ & $2.75 \pm 0.071$ \\
\hline Final acetoin $\left(\mathrm{g} \mathrm{L}^{-1}\right)$ & $1.25 \pm 0.071$ & $18.6 \pm 0.99$ & $1.35 \pm 0.212$ & $17.75 \pm 0.354$ \\
\hline Final 2,3-BDO $\left(\mathrm{g} \mathrm{L}^{-1}\right)$ & $28.75 \pm 0.212$ & $7.7 \pm 0.849$ & $29.05 \pm 0.212$ & $8.15 \pm 0.071$ \\
\hline Final lactic acid $\left(\mathrm{g} \mathrm{L}^{-1}\right)$ & ND & $2.6 \pm 0.283$ & ND & ND \\
\hline Final acetic acid $\left(\mathrm{g} \mathrm{L}^{-1}\right)$ & $1.3 \pm 0.283$ & $2.75 \pm 0.071$ & $1.3 \pm 0.00$ & $1.4 \pm 0.141$ \\
\hline Final ethanol $\left(\mathrm{g} \mathrm{L}^{-1}\right)$ & $5.0 \pm 0.141$ & $4.75 \pm 0.778$ & $5.05 \pm 0.354$ & $5.05 \pm 0.212$ \\
\hline Lactic acid $\left(\mathrm{mol} \mathrm{mol}{ }^{-1}\right)$ & ND & $0.057 \pm 0.006$ & ND & ND \\
\hline Succinic acid yield $\left(\mathrm{mol} \mathrm{mol}^{-1}\right)$ & $0.039 \pm 0.001$ & $0.018 \pm 0.001$ & $0.046 \pm 0.002$ & $0.046 \pm 0.001$ \\
\hline Acetoin yield $\left(\mathrm{mol} \mathrm{mol}{ }^{-1}\right)$ & $0.028 \pm 0.002$ & $0.419 \pm 0.022$ & $0.03 \pm 0.005$ & $0.397 \pm 0.008$ \\
\hline 2,3-BDO yield $\left(\mathrm{mol} \mathrm{mol}^{-1}\right)$ & $0.623 \pm 0.005$ & $0.170 \pm 0.019$ & $0.626 \pm 0.005$ & $0.178 \pm 0.002$ \\
\hline
\end{tabular}

Each date indicates the mean \pm SD from two experiments

$N D$ not detected 
Table 2 The fermentation performance of EC $\Delta$ budC $\Delta$ IdhA strain under different $\mathrm{NaHCO}_{3}$ concentration

\begin{tabular}{|c|c|c|c|c|c|}
\hline $\mathrm{NaHCO}_{3}$ conc. $\left(\mathrm{g} \mathrm{L}^{-1}\right)$ & 0 & 2.5 & 5 & 7.5 & 10 \\
\hline Final pH & $5.43 \pm 0.58$ & $5.92 \pm 0.021$ & $5.94 \pm 0.191$ & $6.2 \pm 0.127$ & $6.56 \pm 0.021$ \\
\hline Consumed glucose $\left(\mathrm{g} \mathrm{L}^{-1}\right)$ & $67.45 \pm 1.626$ & $66.7 \pm 4.808$ & $61 \pm 3.111$ & $64.65 \pm 4.879$ & $67 \pm 0.4 .667$ \\
\hline Final $O_{600}$ & $4.21 \pm 0.078$ & $5.155 \pm 0.007$ & $5.305 \pm 0.064$ & $5.84 \pm 0.113$ & $5.79 \pm 0.226$ \\
\hline Final succinic acid $\left(\mathrm{g} \mathrm{L}^{-1}\right)$ & $1.15 \pm 0.212$ & $1.5 \pm 0.283$ & $1.4 \pm 0.141$ & $1.45 \pm 0.212$ & $1.55 \pm 0.212$ \\
\hline Final acetoin $\left(\mathrm{g} \mathrm{L}^{-1}\right)$ & $16.45 \pm 0.212$ & $15.3 \pm 1.273$ & $13.3 \pm 0.707$ & $14.7 \pm 1.414$ & $12.4 \pm 1.556$ \\
\hline Final 2,3-BDO $\left(\mathrm{g} \mathrm{L}^{-1}\right)$ & $3 \pm 0.283$ & $2.65 \pm 0.212$ & $2 \pm 0.141$ & $2.7 \pm 0.283$ & $1.95 \pm 0.495$ \\
\hline Final lactic acid $\left(\mathrm{g} \mathrm{L}^{-1}\right)$ & ND & ND & ND & ND & ND \\
\hline Final acetic acid $\left(\mathrm{g} \mathrm{L}^{-1}\right)$ & ND & ND & $0.9 \pm 0$ & $1.2 \pm 0$ & $1.5 \pm 0.141$ \\
\hline Final ethanol $\left(\mathrm{g} \mathrm{L}^{-1}\right)$ & $6.25 \pm 0.354$ & $6.8 \pm 0.283$ & $6.15 \pm 0.212$ & $6.05 \pm 0.212$ & $6.1 \pm 0.566$ \\
\hline Succinic acid yield $\left(\mathrm{mol} \mathrm{mol}^{-1}\right)$ & $0.026 \pm 0.004$ & $0.034 \pm 0.004$ & $0.032 \pm 0.02$ & $0.034 \pm 0.02$ & $0.036 \pm 0.01$ \\
\hline Acetoin yield $\left(\mathrm{mol} \mathrm{mol}^{-1}\right)$ & $0.499 \pm 0.018$ & $0.469 \pm 0.005$ & $0.446 \pm 0.001$ & $0.465 \pm 0.01$ & $0.381 \pm 0.028$ \\
\hline 2,3-BDO yield $\left(\mathrm{mol} \mathrm{mol}^{-1}\right)$ & $0.089 \pm 0.011$ & $0.079 \pm 0.001$ & $0.066 \pm 0.001$ & $0.083 \pm 0.002$ & $0.059 \pm 0.019$ \\
\hline
\end{tabular}

Each date indicates the mean \pm SD from two experiments

ND not detected

$10 \mathrm{~g} \mathrm{~L}^{-1} \mathrm{NaHCO}_{3}$ addition, respectively. When grown in fermentation medium supplemented with different $\mathrm{NaHCO}_{3}$ levels $\left(0,2.5,5,7.5\right.$, and $\left.10 \mathrm{~g} \mathrm{~L}^{-1}\right)$, the concentrations of succinic acid were slightly enhanced from 1.15 to $1.55 \mathrm{~g} \mathrm{~L}^{-1}$ within $24 \mathrm{~h}$. The maximum acetoin and succinic acid yields (0.469 and $0.034 \mathrm{~mol} \mathrm{~mol}^{-1}$ glucose) were obtained when $2.5 \mathrm{~g} \mathrm{~L}^{-1} \mathrm{NaHCO}_{3}$ was added. Furthermore, the cell growth and acetic acid titer were also improved, while the amount of 2,3-butanediol slightly decreased. Therefore, the optimum $\mathrm{NaHCO}_{3}$ concentration for the combined production of acetoin and succinic acid was $2.5 \mathrm{~g} \mathrm{~L}^{-1}$.

\section{Fed-batch fermentation for co-production of acetoin and succinic acid}

To increase the production of acetoin and succinic acid, fed-batch fermentation was performed using strain EC $\Delta$ budC $\Delta$ ldhA with an initial glucose concentration of $57.8 \mathrm{~g} \mathrm{~L}^{-1}$. $\mathrm{NaHCO}_{3}\left(1 \mathrm{~g} \mathrm{~L}^{-1}\right)$ was added at fermentation times of 6 and $12 \mathrm{~h}$. Next, glucose $\left(20 \mathrm{~g} \mathrm{~L}^{-1}\right)$ and $\mathrm{NaHCO}_{3}\left(2 \mathrm{~g} \mathrm{~L}^{-1}\right)$ were added simultaneously at 24,36 , $48,60,72$, and $84 \mathrm{~h}$ of fermentation.

Figure 3 shows $47.6 \mathrm{~g} \mathrm{~L}^{-1}$ acetoin and $7.35 \mathrm{~g} \mathrm{~L}^{-1}$ succinic acid from $171.25 \mathrm{~g} \mathrm{~L}^{-1}$ glucose obtained in $96 \mathrm{~h}$ by the EC $\triangle$ budC $\Delta$ ldhA strain. The acetoin and succinic acid yields were 0.568 and $0.065 \mathrm{~mol} \mathrm{~mol}^{-1}$ glucose, respectively. In fed-batch fermentation, the maximum acetoin and succinic acid yields were obtained as 0.565 and $0.071 \mathrm{~mol} \mathrm{~mol}^{-1}$ glucose, respectively, after $72 \mathrm{~h}$. Compared with batch fermentation (Table 2), the maximum acetoin and succinic acid yields of fed-batch fermentation were increased by 1.2- and 2-fold, respectively. The results indicated that the acetoin and succinic acid co-production of the EC $\Delta$ budC $\Delta$ ldhA strain was improved by fed-batch fermentation.

\section{Optimization of fed-batch fermentation for co-production of acetoin and succinic acid}

A previous study showed that after glucose was depleted, the accumulated products were reused by Klebsiella pneumoniae as a carbon source [2]. Our previous work also found that with a low glucose concentration during cultivation, succinic acid did not accumulate (data not shown). To prevent the exhaustion of glucose, the glucose concentration was increased during fed-batch fermentation to achieve higher acetoin and succinic acid co-production. In this study, the optimal conditions for acetoin and succinic acid fermentation were determined by the glucose and $\mathrm{NaHCO}_{3}$ times and modes of feeding. The initial glucose and $\mathrm{NaHCO}_{3}$ concentrations were $60 \mathrm{~g} \mathrm{~L}^{-1}$ and $2.5 \mathrm{~g} \mathrm{~L}^{-1}$, respectively. When the glucose concentration was reduced to approximately $30 \mathrm{~g} \mathrm{~L}^{-1}$, glucose was added to the fermentation medium. Glucose (25, 35,35 and $35 \mathrm{~g} \mathrm{~L}^{-1}$ ) was added at $12,24,36$ and $48 \mathrm{~h}$ of fermentation, respectively. $\mathrm{NaHCO}_{3}(1,1,5,5,5$, and $2 \mathrm{~g} \mathrm{~L}^{-1}$ ) was added at $6,12,24,36,48$, and $60 \mathrm{~h}$ of fermentation, respectively. The time-course results of the production of succinic acid are shown in Fig. 4. After growth for $72 \mathrm{~h}$, the maximum production of acetoin and succinic acid was measured as $39.5 \mathrm{~g} \mathrm{~L}^{-1}$ and $20.3 \mathrm{~g} \mathrm{~L}^{-1}$, respectively, in optimized fed-batch fermentation. The acetoin and succinic acid yields were 0.439 and $0.168 \mathrm{~mol} \mathrm{~mol}^{-1}$ glucose, respectively. The maximum acetoin and succinic acid yields were obtained as 0.559 and $0.322 \mathrm{~mol} \mathrm{~mol}^{-1}$ glucose, after 36 h. Compared with fed-batch fermentation (Fig. 3), 

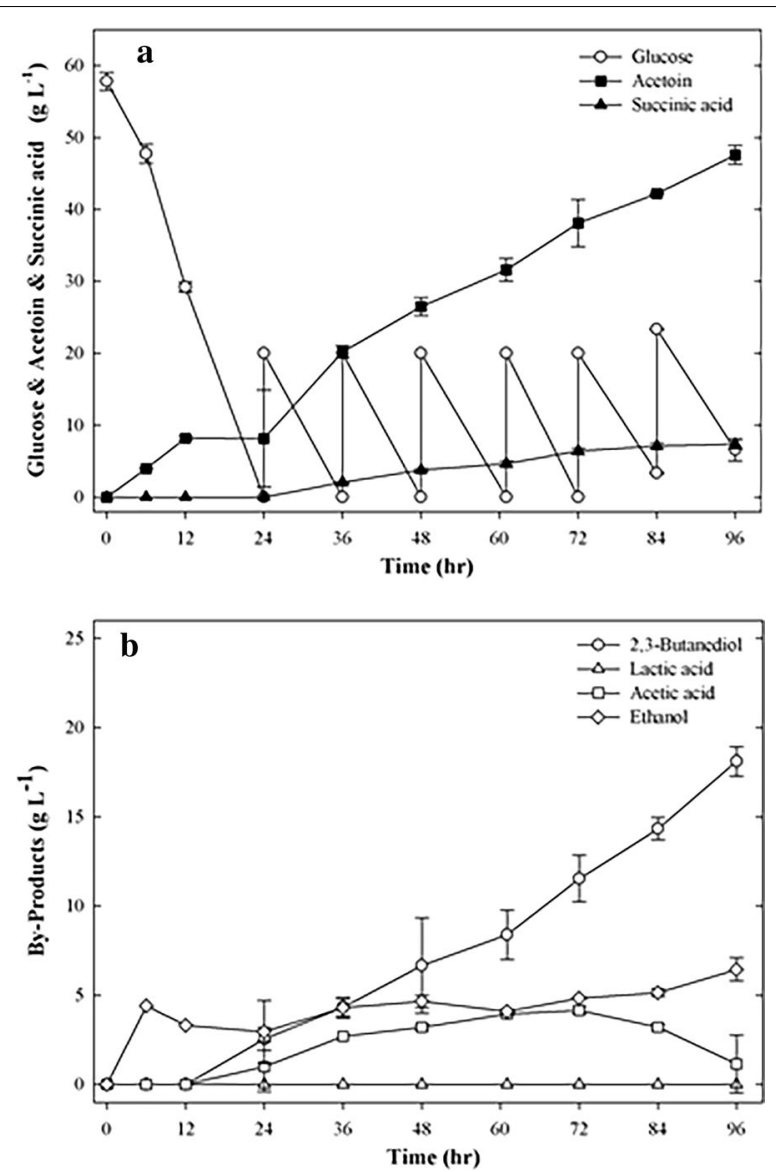

Fig. 3 Time course of fed-batch fermentation of EC $\Delta$ budC $\triangle I d h A$. a Glucose, acetoin, succinic acid, $\mathbf{b}$ by-product. The experiments were conducted in $50 \mathrm{~mL}$ of fermentation medium containing $60 \mathrm{~g} \mathrm{~L}^{-1}$ glucose in a $250 \mathrm{~mL}$ flask. $\mathrm{NaHCO}_{3}\left(1 \mathrm{~g} \mathrm{~L}^{-1}\right)$ was added at 6 and $12 \mathrm{~h}$ of fermentation. After that, $\mathrm{NaHCO}_{3}\left(2 \mathrm{~g} \mathrm{~L}^{-1}\right)$ was added at $24,36,48,61,72$, and $84 \mathrm{~h}$ of fermentation. Glucose $\left(20 \mathrm{~g} \mathrm{~L}^{-1}\right)$ was added at $24,36,48,61,72$, and $84 \mathrm{~h}$ of fermentation. Samples were withdrawn every $12 \mathrm{~h}$ for detection of cell density and concentration of substrates and products
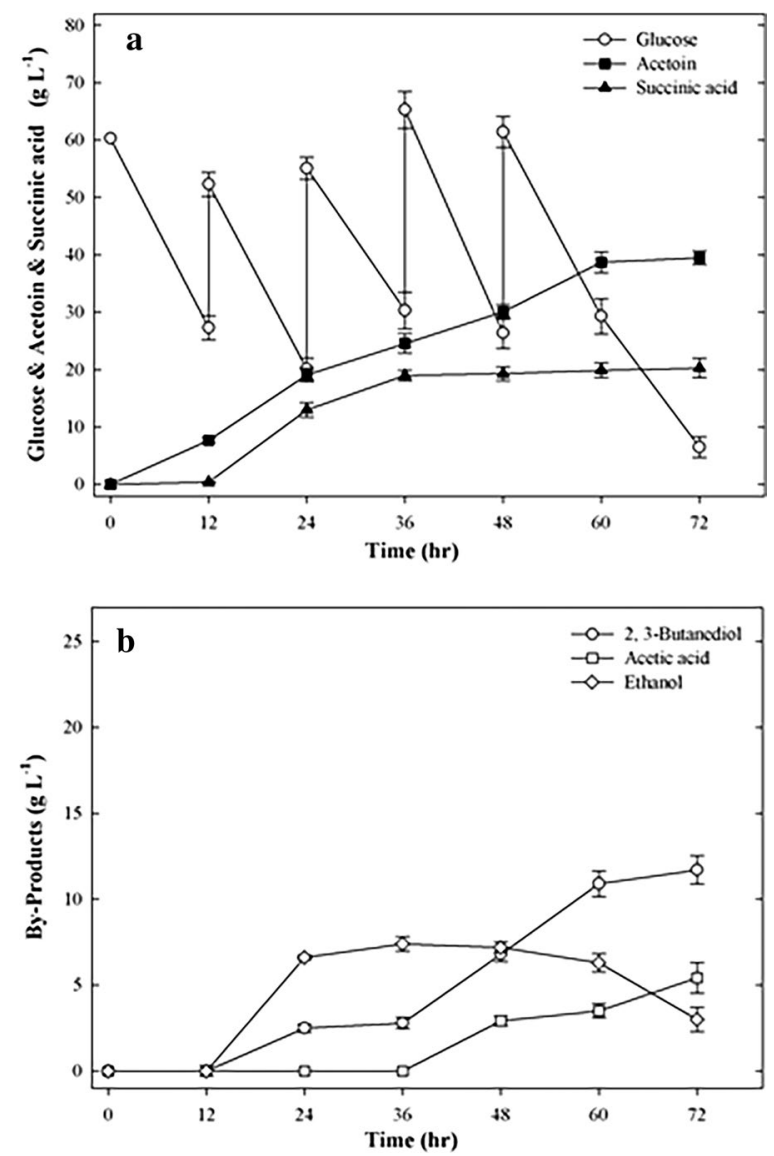

Fig. 4 Time course of acetoin and succinic acid co-production by fed-batch fermentation using strain EC $\triangle$ budC $\triangle$ IdhA under the optimized conditions. a Glucose, acetoin, succinic acid, $\mathbf{b}$ by-product. The experiments were conducted in $50 \mathrm{~mL}$ of fermentation medium containing $60 \mathrm{~g} \mathrm{~L}^{-1}$ glucose in a $250 \mathrm{~mL}$ flask. $\mathrm{NaHCO}_{3}(2.5,1,1$, $5,5,5$ and $\left.2 \mathrm{~g} \mathrm{~L}^{-1}\right)$ was added at $0,6,12,24,36,48$, and $60 \mathrm{~h}$ of fermentation, respectively. Glucose $\left(60,25,35,35\right.$, and $\left.35 \mathrm{~g} \mathrm{~L}^{-1}\right)$ was added at $0,12,24,36$, and $48 \mathrm{~h}$ of fermentation, respectively. Samples were withdrawn every $12 \mathrm{~h}$ for detection of cell density and concentration of substrates and products the succinic acid titer of optimized fed-batch fermentation was increased by 2.8 -fold. However, when only the $b u d C$ gene was deleted, we found that a large amount of lactic acid $\left(15 \mathrm{~g} \mathrm{~L}^{-1}\right)$ was produced under the same optimized conditions, and caused a decrease in the production of succinic acid (Additional file 1: Fig. S1). This is similar to the results in Table 1. Thus, deletion of the $l d h A$ gene of $E$. cloacae is required. The results indicated that the succinic acid production of the EC $\Delta$ budC $\Delta$ ldhA strain was significantly increased by optimizing the glucose and $\mathrm{NaHCO}_{3}$ feeding mode and time during fermentation, further enhancing the co-production concentrations of acetoin and succinic acid.

\section{Fed-batch fermentation for co-production of acetoin and succinic acid in a bioreactor}

Previous studies have shown that cultivating the EC $\Delta$ budC $\Delta$ ldhA strain in a $250 \mathrm{~mL}$ flask through an optimized fed-batch culture method can increase the production of acetoin and succinic acid. Therefore, the same optimized fed-batch fermentation conditions were implemented in a 3-L bioreactor.

As shown in Fig. 5, the initial glucose and $\mathrm{NaHCO}_{3}$ concentrations were $60 \mathrm{~g} \mathrm{~L}^{-1}$ and $2.5 \mathrm{~g} \mathrm{~L}^{-1}$, respectively. Glucose $\left(25,35,25,10\right.$, and $\left.10 \mathrm{~g} \mathrm{~L}^{-1}\right)$ was added at $12,24,36,48$, and $60 \mathrm{~h}$ of fermentation, respectively. $\mathrm{NaHCO}_{3}\left(1,1,5,5,5\right.$, and $\left.2 \mathrm{~g} \mathrm{~L}^{-1}\right)$ was added at 6,12 , $24,36,48$, and $60 \mathrm{~h}$ of fermentation, respectively. The 

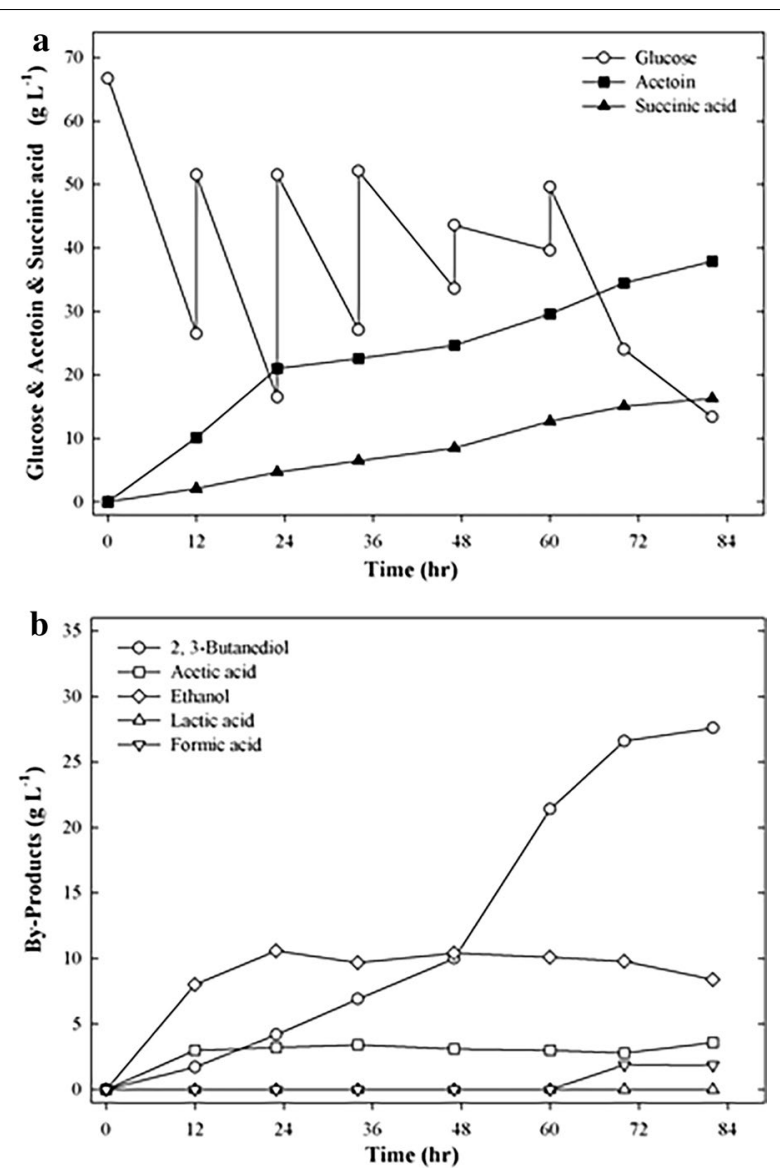

Fig. 5 Time course of acetoin and succinic acid co-production by fed-batch fermentation using strain EC $\triangle$ budC $\triangle \mathrm{ldhA}$ in bioreactor. a Glucose, acetoin, succinic acid, b by-product. The experiments were conducted in 1.5- $\mathrm{L}$ of fermentation medium containing $60 \mathrm{~g} \mathrm{~L}^{-1}$ glucose under $0.5 \mathrm{vvm}$ air flow in 3-L bioreactor. $\mathrm{NaHCO}_{3}(2.5,1$, $1,5,5,5$, and $2 \mathrm{~g} \mathrm{~L}^{-1}$ ) was added at $0,6,12,24,36,48$, and $60 \mathrm{~h}$ of fermentation, respectively. Glucose $\left(60,25,35,25,10\right.$, and $\left.10 \mathrm{~g} \mathrm{~L}^{-1}\right)$ was added at $0,12,24,36,48$, and $60 \mathrm{~h}$ of fermentation, respectively. Samples were withdrawn every $12 \mathrm{~h}$ for detection of cell density and concentration of substrates and products

time-course results are shown in Fig. 5. After growth for $82 \mathrm{~h}$, the maximum production of acetoin and succinic acid was measured as $38 \mathrm{~g} \mathrm{~L}^{-1}$ and $16.3 \mathrm{~g} \mathrm{~L}^{-1}$, respectively. The acetoin and succinic acid yields were 0.490 and $0.157 \mathrm{~mol} \mathrm{~mol}^{-1}$ glucose, respectively.

\section{Discussion}

Several studies have also shown that the inactivation of budC significantly improves the production of acetoin. Indeed, previous reports have shown that the deletion of the budC gene could decrease 2,3-butanediol. Three butanediol stereoisomers, namely, (2R,3R)-2,3-butanediol, (2S,3S)-2,3-butanediol, and meso-2,3-butanediol, are found in many bacterial species, such as
Enterobacter cloacae [10, 22], Klebsiella pneumoniae [23], and Bacillus licheniformis [24], and meso-2,3-butanediol and (2S,3S)-2,3-butanediol are the major forms that accumulate in E. cloacae [25]. However, when the budC gene was deleted, a small amount of 2,3-butanediol could still be detected [3, 22, 23, 26, 27]. In this study, the budC gene was knocked out, and we observed that the production of meso-2,3-butanediol and (2S,3S)-2,3-butanediol decreased (data not shown).

A previous study characterized a budC and glycerol dehydrogenase (encoded by gldA and $d h a D$ )-deficient Klebsiella pneumoniae strain, which removes 2,3-butanediol under conditions wherein glycerol is used as a carbon source. These findings suggested that dhaD and gldA may be involved in 2,3-butanediol formation [22]. Another study reported diacetyl production by inactivating budA, budC, and diacetyl reductases (also known as glycerol dehydrogenase, encoded by $g d h$ ) in E. cloacae SDM. When the $g d h$ and budC genes were both inactivated in the strain E. cloacae SDM ( $\triangle$ budA), (2R,3R) 2,3-butanediol could be slightly detected [10]; these results show that there is a third enzyme responsible for 2,3-butanediol production in the E. cloacae strain. In the present work, disruption of the budC gene remarkably decreased the production of 2,3-butanediol by almost 2.7-fold compared to that of the wild type and ECAldhA strains (Table 1). However, small amounts of 2,3-butanediol were still detected in a few of the EC $\Delta$ budC and EC $\Delta$ budC $\Delta$ ldhA strains, indicating the presence of other genes encoding enzymes that convert acetoin to 2,3-butanediol in E. cloacae.

Theoretically, the formation of $1 \mathrm{~mol}$ succinic acid from glucose requires $1 \mathrm{~mol}$ of $\mathrm{CO}_{2}[20,28]$. Therefore, $\mathrm{CO}_{2}$ is indispensable for succinic acid biosynthesis, and many studies have demonstrated that succinic acid production can be increased by adding $\mathrm{HCO}_{3}{ }^{-}$to the fermentation medium [12, 28]. Cheng et al. [28] increased succinic acid production in $K$. pneumoniae by adding $\mathrm{HCO}_{3}{ }^{-}$to the fermentation medium. In another study, Wu et al. [20] reported yields of $40.67 \mathrm{~g} \mathrm{~L}^{-1} 2,3$-butanediol and $21.79 \mathrm{~g} \mathrm{~L}^{-1}$ succinic acid by adding $\mathrm{NaHCO}_{3}$ to E. cloacae. In this study, supplying $\mathrm{NaHCO}_{3}$ during batch fermentation may enhance succinic acid production by improving the quantity of dissolved $\mathrm{CO}_{2}$ and by increasing the carbon flux to succinic acid. When grown in fermentation medium without $\mathrm{NaHCO}_{3}$, the final acetoin production $\left(16.45 \mathrm{~g} \mathrm{~L}^{-1}\right)$ was slightly higher; however, the final amount of succinic acid produced was only $1.15 \mathrm{~g} \mathrm{~L}^{-1}$. When grown in fermentation medium supplemented with $\mathrm{NaHCO}_{3}$, succinic acid production was $34.8 \%$ higher than the amount produced during batch fermentation without $\mathrm{NaHCO}_{3}$ (Table 2). 
In general, the production of succinic acid was higher under anaerobic conditions, and bacterial producers of succinic acid can be found among facultative and strictly anaerobic rumen bacteria such as Mannheimia succiniciproducens [29], Actinobacillus succinogenes [30], and Anaerobiospirillum succiniciproducens [31]. E. cloacae is a facultative anaerobe, and when it is cultured under anaerobic conditions, the glucose consumption rate of the $\Delta$ budC $\Delta$ ldhA strain is slower, resulting in lower production concentration of acetoin. In addition, when cultured under anaerobic conditions, the $\triangle$ budC $\Delta$ ldhA strain was found to produce lactic acid (Additional file 1: Fig. S2). Although we only knocked out D-lactate dehydrogenase, this may activate other lactate dehydrogenases under anaerobic conditions, such as L-lactate dehydrogenase, leading to the production of lactic acid.

A previous study showed that reducing the carbon flux to lactate, ethanol, and acetate by-products can be performed by deleting the $l d h A, a d h E$, and pta genes in $K$. pneumoniae [32]. In this study, by blocking lactic acid synthesis pathways to redirect more carbon sources to succinic acid synthesis in wild type $E$. cloacae, the engineered EC $\Delta$ budC significantly increased succinic acid yield. This engineering approach may represent a practical strategy involving the deletion of $l d h A$ and $b u d C$ genes to reduce carbon flux towards the formation of by-products.

\section{Conclusions}

In this study, we engineered an E. cloacae budC and ldhA double-deletion strain (namely, EC $\Delta$ budC $\Delta$ ldhA) to produce succinic acid and acetoin. The highest acetoin and succinic acid titers achieved by this engineered strain were 39.5 and $20.3 \mathrm{~g} \mathrm{~L}^{-1}$, respectively, during optimization of fed-batch fermentation conditions. Our findings demonstrated that the EC $\Delta$ budC $\Delta$ ldhA strain would be useful for the simultaneous production of commercial products (acetoin and succinic acid) and the prevention of by-product formation, thus reducing the cost of microbial fermentation in a single step.

\section{Methods}

\section{Bacterial strains}

The strains used in this study are described in Table 3. Escherichia coli and E. cloacae were grown in LB broth with rotary shaking agitation at $200 \mathrm{rpm}$ at $37{ }^{\circ} \mathrm{C}$ and $35{ }^{\circ} \mathrm{C}$, respectively. Ampicillin $\left(100 \mu \mathrm{g} \mathrm{mL}^{-1}\right)$ and kanamycin $\left(50 \mu \mathrm{g} \mathrm{mL}^{-1}\right)$ were added to LB broth. E. cloacae (CICC 10011) was purchased from the China Center of Industrial Culture Collection (China). E. coli DH5 $\alpha$ was used as the host for all recombinant plasmid constructs. E. coli S17-1 $\lambda$ pir, which is able to host pKR6K and its derivatives, was used for conjugation with $E$. cloacae.

Table 3 Strains and plasmid used in this study

\begin{tabular}{|c|c|c|}
\hline Name & Relevant genotype & Source and ref \\
\hline \multicolumn{3}{|l|}{ Strains } \\
\hline $\mathrm{DH} 5 \mathrm{a}$ & 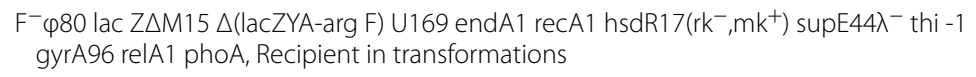 & Sangon Biotech \\
\hline S17-1 $\lambda$ pir & $\begin{array}{l}\text { RP4-2(Km::Tn7,Tc::Mu-1) pro-82 LAMpir recA1 endA1 thiE1 hsdR17 creC510; conjuga- } \\
\text { tive strain able to host -pir-dependent plasmids }\end{array}$ & Zoman Biotechnology \\
\hline E. cloacae CICC 10011 & Wild type & $\mathrm{CICC}$ \\
\hline EC $\triangle$ budC & E. cloacae CICC 10011 budC disruption mutant strain & This study \\
\hline EC $\triangle \mathrm{ldhA}$ & E. cloacae CICC 10011 IdhA disruption mutant strain & This study \\
\hline EC $\triangle$ budC $\triangle \mathrm{ldhA}$ & E. cloacae CICC 10011 budC and IdhA disruption mutant strain & This study \\
\hline \multicolumn{3}{|l|}{ Plasmid } \\
\hline pGEM-T Easy Vector & Cloning vector, $\mathrm{Ap}^{\mathrm{r}}$ & Promega \\
\hline pToriR6K & pGEM-T Easy Vector with 0.6-kb oriR6K fragment, Ap ${ }^{r}$ & This study \\
\hline pTBCup & pGEM-T Easy Vector with 0.5-kb budC upstream fragment, Ap ${ }^{r}$ & This study \\
\hline pTBCdown & pGEM-T Easy Vector with 0.5-kb budC downstream fragment, $A p^{r}$ & This study \\
\hline pTLAup & pGEM-T Easy Vector with 0.5-kb IdhA upstream fragment, $\mathrm{Ap}^{\mathrm{r}}$ & This study \\
\hline pTLAdown & pGEM-T Easy Vector with 0.5-kb IdhA downstream fragment, $\mathrm{Ap}^{\mathrm{r}}$ & This study \\
\hline pK18mobsacB & oriT(RP4) sacB lacZa Plac Pmbi; mobilization and counterselection, Kan ${ }^{r}$ & $\mathrm{BCRC}$ \\
\hline $\mathrm{pRL} 27$ & Mini-Tn5 transposon (oriR6K) delivery vector, Kanr & {$[33]$} \\
\hline pKR6K & R6K replicon; gene replacement vector, $\operatorname{Kan}^{r}$ & This study \\
\hline $\mathrm{pK} \triangle \mathrm{budC}$ & pKR6K derivative, carries a 771 bp deletion of budC, Kan $^{r}$ & This study \\
\hline $\mathrm{pK} \Delta \mathrm{ldhA}$ & pKR6K derivative, carries a 990 bp deletion of IdhA, Kan ${ }^{r}$ & This study \\
\hline
\end{tabular}




\section{Plasmid construction}

Plasmids constructed and used are described in Table 3. The gene replacement vector of E. cloacae was constructed by a previously described method [22]. The R6K origin of replication was amplified with primers (BspHIoriR6K-F and BsaXI-oriR6K-R) using the plasmid pRL27 as a template. The $0.6 \mathrm{~kb}$ oriR6K fragment was ligated to the pGEM-T Easy vector (Promega, Madison, WI, USA) to create the plasmid pToriR6K. The oriR6K fragment (BspHI/BsaXI) was digested from pToriR6K and cloned into plasmid pK18mobsacB to create the suicide plasmid pKR6K. The plasmid pKR6K was used for gene knockout by homologous recombination in E. cloacae.

Gene knockout mutants of $E$. cloacae were constructed using the suicide vector pKR6K. To construct the budC and $l d h A$ gene replacement vector of $E$. cloacae, the selected flanks were $510 \mathrm{bp}$ long and homologous to sequences upstream and downstream of the region targeted for deletion. The upstream and downstream flanking sequences of the budC and $l d h A$ genes were amplified with their respective primers (EcoRI-budCup-F/EcoRIbudCup-R, XbaI-budCdown-F/SphI-budCdown-R and EcoRI-ldhAup-F/BamHI-EcoRI-ldhAup-R, XbaI-ldhAdown-F/SphI-SalI-ldhAdown-R) using the total genomic DNA of E. cloacae as a template for PCR and cloned into the pGEM-T Easy vector to generate plasmids pTBCup and pTBCdown. Then, the budC upstream and downstream fragments were digested by EcoRI and $X b a \mathrm{I} / S p h \mathrm{I}$ from plasmids pTBCup and pTBCdown, respectively. The two fragments were ligated to pKR6K digested with EcoRI and $X b a \mathrm{I} / S p h \mathrm{I}$, producing $\mathrm{pK} \Delta \mathrm{budC}$. The ldhA upstream and downstream fragments were digested by EcoRI and $\mathrm{XbaI} / \mathrm{SalI}$ from plasmids pTLAup and pTLAdown, respectively. The two fragments were ligated to pKR6K digested with EcoRI and $\mathrm{XbaI} / \mathrm{SalI}$, producing $\mathrm{pK} \Delta \mathrm{ldhA}$. Then, the plasmids $\mathrm{pK} \Delta \mathrm{budC}$ and $\mathrm{pK} \Delta \mathrm{ldhA}$ were transformed into E. coli S17-1. E. coli S17-1 (pK $\Delta$ budC and $\mathrm{pK} \Delta \mathrm{ldhA}$ ) was used as the donor in conjugation with $E$. cloacae. The primer sequences are shown in Table 4.

\section{Gene knockout in the chromosome of E. cloacae}

Allelic exchange of E. cloacae was performed as previously described [10] with slight modifications. The constructed strains used are described in Table 3. Strain EC $\triangle$ budC was constructed by allelic exchange of plasmid $\mathrm{pK} \Delta$ budC into E. cloacae. Strain EC $\Delta$ ldhA was constructed by allelic exchange of plasmid pK $\Delta$ ldhA into E. cloacae. Strain EC $\Delta$ budC $\Delta$ ldhA was constructed by allelic exchange of plasmid $\mathrm{pK} \Delta \mathrm{ldhA}$ into E. cloacae strain EC $\Delta$ budC. Colonies with confirmed deletions were screened by PCR using specific primers. The primer sequences are shown in Table 4.

\section{Batch and fed-batch fermentations}

The seed culture, batch fermentation, and fed-batch fermentation were carried out according to the procedure described by Wu et al. [20]. Sterilized glucose was added before fermentation. Wild type and gene knockout

Table 4 Primers used in this study

\begin{tabular}{|c|c|c|}
\hline Primer & Sequence & References or source \\
\hline BspHI-oriR6K-F & 5'-aatttcatgacagttcaacctgttgatagtac-3' & {$[23]$} \\
\hline BsaXI-oriR6K-R & 5'-aattggagaggcggtagagagagacaatgtcagccgttaagtgttc-3' & {$[23]$} \\
\hline EcoRl-budCup-F & 5'-aattgaattcagcttccacatctggatcgcccgct-3' & This study \\
\hline EcoRl-budCup-R & 5'-aattgaattcttctctgtccttatagtgagtcaca-3' & This study \\
\hline Xbal-budCdown-F & 5'-aatttctagataaattctaataagctctgacatga-3' & This study \\
\hline Sphl-budCdown-R & 5'-aattgcatgccttcatcgtgcgcatttcgcccggc-3' & This study \\
\hline budC-up-F & 5'-aggacatcgtcaataacgacgtgac-3' & This study \\
\hline budC-down-R & $5^{\prime}$-ttcatcttcggtaaagatcagcgtg-3' & This study \\
\hline budC-F & $5^{\prime}$-atgcaaaaagttgctctcgtaaccg-3' & This study \\
\hline budC-R & 5'-ttagttgaacaccatcccaccatca-3' & This study \\
\hline EcoRI-IdhAup-F & 5' -aattgaattcaccgtgttaagttcaagcgcaccaa-3' & This study \\
\hline BamHI-EcoRI-IdhAup-R & 5'-aattggatccgaattcaagactttctccagtgattttacat-3' & This study \\
\hline Xbal-IdhAdown-F & 5'-aatttctagagccgacatgccgggtggcggttacg-3' & This study \\
\hline Sphl-Sall-IdhAdown-R & 5'-aattgcatgcgtcgacggcgacggtcattatttcgcaggcg-3' & This study \\
\hline IdhA-up-F & $5^{\prime}$-tttttggcgcaacggttgacggtgc-3' & This study \\
\hline IdhA-down-R & 5'-atgcgggtcgecgccgcgectgcca-3' & This study \\
\hline IdhA-F & 5'-atgaaactcgcggtatatagcacaa-3' & This study \\
\hline IdhA-R & 5'-ttagactatctcgttaggacacgct-3' & This study \\
\hline
\end{tabular}


strains of E. cloacae were inoculated into flasks $(250 \mathrm{~mL})$ containing $50 \mathrm{~mL}$ of seed culture medium and cultured overnight at $35{ }^{\circ} \mathrm{C}$ with continuous shaking at $150 \mathrm{rpm}$. The fermentation medium contained final concentrations of $5 \%(\mathrm{v} / \mathrm{v})$ seed medium.

Batch fermentation and fed-batch fermentation were conducted in $250 \mathrm{~mL}$ flasks containing $50 \mathrm{~mL}$ of medium. Cultivation was carried out at $35{ }^{\circ} \mathrm{C}$ with a speed at $150 \mathrm{rpm}$. The $\mathrm{pH}$ was maintained by the addition of $\mathrm{NaHCO}_{3}$. Samples were withdrawn periodically to measure the $\mathrm{OD}_{600}$ and the concentrations of glucose, succinic acid, acetoin, and by-products. Each experiment described in this research was performed in two replicates.

\section{Fed-batch fermentations in the bioreactor}

Seed culture $(5 \%, \mathrm{v} / \mathrm{v})$ was inoculated into the fermentation medium, and fed-batch fermentation was carried out in a 3-L stirred-vessel bioreactor (BLBIO-3GC, Bailun, China) containing 1.5-L of fermentation medium under $0.5 \mathrm{vvm}$ air flow. Cultivation was performed at $35^{\circ} \mathrm{C}$ with a speed at $300 \mathrm{rpm}$ and an aeration rate of $0.5 \mathrm{vvm}$. The $\mathrm{pH}$ was maintained by the addition of $\mathrm{NaHCO}_{3}$.

\section{Analytical methods}

Glucose, succinic acid, acetoin, and by-products were analyzed by the methods described in $\mathrm{Wu}$ et al. [20]. Samples were measured by HPLC (LC20, Shimadzu, Japan) using an Aminex HPX-87H column (Bio Rad, USA) with a refractive index detector (RID-20A).

\section{Supplementary Information}

The online version contains supplementary material available at https://doi. org/10.1186/s13068-021-01878-1.

Additional file 1: Fig. S1. Time course of fed-batch fermentation of EC $\triangle$ budC under the optimized conditions. Fig. S2. Time course of batch anaerobic fermentation of EC $\triangle$ budC $\triangle \mathrm{ldhA}$.

\section{Acknowledgements}

The authors would like to thank Dr. Te-Jin Chow of Fooying University for their assistance with the gene knockout method of the work.

\section{Authors' contributions}

HYS performed the construction of the metabolically engineered strains and cultivation experiments. HYL and CYX performed the fermentation experiments and product analysis. KKC and QF designed the experiments and prepared/polished the manuscript. All authors read and approved the final manuscript.

\section{Funding}

This work was supported by the High-level Talents Project of Dongguan University of Technology (KCYKYQD2017017, KCYCXPT2017007) and the Guangdong Innovation Research Team for Higher Education (2017KCXTD030).

\section{Availability of data and materials}

The datasets supporting the conclusions of this article are included within the article.
Ethics approval and consent to participate Not applicable.

\section{Consent for publication}

All authors consented to the publication of this work.

\section{Competing interests}

The authors declare that they have no competing interests.

\section{Author details}

${ }^{1}$ Engineering Research Center of Health Food Design \& Nutrition Regulation, School of Chemical Engineering and Energy Technology, Dongguan University of Technology, Dongguan 523808, China. ${ }^{2}$ School of Chemical Engineering and Technology, Xi'an Jiaotong University, Xi'an 710049, China. ${ }^{3}$ China-Latin America Joint Laboratory for Clean Energy and Climate Change, School of Chemical Engineering and Energy Technology, Dongguan University of Technology, Dongguan 523808, China.

Received: 9 September 2020 Accepted: 7 January 2021

Published online: 19 January 2021

\section{References}

1. Werpy T, Petersen G. Top value added chemicals from biomass—volume 1: results of screening for potential candidates from sugars and synthesis gas. U.S. Department of Energy. 2004.

2. Wang D, Zhou J, Chen C, Wei D, Shi J, Jiang B, Liu P, Hao J. R-acetoin accumulation and dissimilation in Klebsiella pneumoniae. J Ind Microbiol Biotechnol. 2015;42:1105-15.

3. Zhang L, Liu Q, Ge Y, Li L, Gao C, Xu P, Ma C. Biotechnological production of acetoin, a bio-based platform chemical, from a lignocellulosic resource by metabolically engineered Enterobacter cloacae. Green Chem. 2016;18:1560-70.

4. Sun JA, Zhang LY, Rao B, Shen YL, Wei DZ. Enhanced acetoin production by Serratia marcescens $\mathrm{H} 32$ with expression of a water-forming NADH oxidase. Bioresour Technol. 2012;119:94-8.

5. Xu H, Jia S, Liu J. Development of a mutant strain of Bacillus subtilis showing enhanced production of acetoin. Afr J Biotechnol. 2011;10:779-88.

6. Celińska E, GrajekW. Biotechnological production of 2, 3-butanediolCurrent state and prospects. Biotechnol Adv. 2009;27:715-25.

7. Gao S, Guo W, Shi L, Yu Y, Zhang C, Yang H. Characterization of acetoin production in a budC gene disrupted mutant of Serratia marcescens G12. $J$ Ind Microbiol Biotechnol. 2014;41:1267-74.

8. Bae SJ, Kim S, Hahn JS. Efficient production of acetoin in Saccharomyces cerevisiae by disruption of 2,3-butanediol dehydrogenase and expression of NADH oxidase. Sci Rep. 2016;6:27667.

9. Jang JW, Jung HM, Im DK, Jung MY, Oh MK. Pathway engineering of Enterobacter aerogenes to improve acetoin production by reducing byproducts formation. Enzyme Microb Technol. 2017;106:114-8.

10. Zhang L, Zhang Y, Liu Q, Meng L, Hu M, Lv M, Li K, Gao C, Xu P, Ma C. Production of diacetyl by metabolically engineered Enterobacter cloacae. Sci Rep. 2015;5:9033.

11. Beauprez JJ, De Mey M, Soetaert WK. Microbial succinic acid production: natural versus metabolic engineered producers. Process Biochem. 2010;45:1103-14.

12. Song $\mathrm{H}$, Lee JW, Choi S, You JK, Hong WH, Lee SY. Effects of dissolved $\mathrm{CO}_{2}$ levels on the growth of Mannheimia succiniciproducens and succinic acid production. Biotechnol Bioeng. 2007;98:1296-304.

13. Cheng KK, Wu J, Wang GY, Li WY, Feng J, Zhang JA. Effects of pH and dissolved $\mathrm{CO}_{2}$ level on simultaneous production of 2, 3-butanediol and succinic acid using Klebsiella pneumoniae. Bioresour Technol. 2013;135:500-3.

14. Clark DP. The fermentation pathways of Escherichia coli. FEMS Microbiol Rev. 1989:5:223-34

15. Olajuyin AM, Yang M, Mu T, Sharshar MM, Xing J. Succinate production with metabolically engineered Escherichia coli using elephant grass stalk (Pennisetum purpureum) hydrolysate as carbon source. Waste Biomass Valorization. 2020;11:1717-25.

16. Kang Z, Gao C, Wang Q, Liu H, Qi Q. A novel strategy for succinate and polyhydroxybutyrate co-production in Escherichia coli. Bioresour Technol. 2010;101:7675-8 
17. Tan Z, Zhu X, Chen J, Li Q, Zhang X. Activating phosphoenolpyruvate carboxylase and phosphoenolpyruvate carboxykinase in combination for improvement of succinate production. Appl Environ Microbiol. 2013;79:4838-44.

18. Wang J, Zhu J, Bennett GN, San KY. Succinate production from different carbon sources under anaerobic conditions by metabolic engineered Escherichia coli strains. Metab Eng. 2011;13:328-35.

19. Lan El, Wei CT. Metabolic engineering of cyanobacteria for the photosynthetic production of succinate. Metab Eng. 2016;38:483-93.

20. Wu J, Liu HJ, Yan X, Zhou YJ, Lin ZN, Cheng KK, Zhang JA. Co-production of 2,3-BDO and succinic acid using xylose by Enterobacter cloacae. J Chem Technol Biotechnol. 2017;93:1462-7.

21. Jung MY, Ng CY, Song H, Lee J, Oh MK. Deletion of lactate dehydrogenase in Enterobacter aerogenes to enhance 2, 3-butanediol production. Appl Microbiol Biotechnol. 2012;95:461-9.

22. Li L, Li K, Wang Y, Chen C, Xu Y, Zhang L, Han B, Gao C, Tao F, Ma C, Xu P. Metabolic engineering of Enterobacter cloacae for high-yield production of enantiopure (2R,3R)-2,3-butanediol from lignocellulose-derived sugars. Metab Eng. 2015;28:19-27.

23. Wang Y, Tao F, Xu P. Glycerol dehydrogenase plays a dual role in glycerol metabolism and 2, 3-butanediol formation in Klebsiella pneumoniae. J Biol Chem. 2014;289:6080-90.

24. Li L, Zhang L, Li K, Wang Y, Gao C, Han B, Ma C, Xu P. A newly isolated Bacillus licheniformis strain thermophilically produces 2,3-butanediol, a platform and fuel bio-chemical. Biotechnol Biofuels. 2013;6:123.

25. Xu Y, Chu H, Gao C, Tao F, Zhou Z, Li K, Li L, Ma C, Xu P. Systematic metabolic engineering of Escherichia coli for high-yield production of fuel bio-chemical 2,3-butanediol. Metab Eng. 2014;23:22-33.

26. Chen C, Wei D, Shi J, Wang M, Hao J. Mechanism of 2, 3-butanediol stereoisomer formation in Klebsiella pneumoniae. Appl Microbiol Biotechnol. 2014:98:4603-13.
27. Qi G, Kang Y, Li L, Xiao A, Zhang S, Wen Z, Xu D, Chen S. Deletion of meso2,3-butanediol dehydrogenase gene bud C for enhanced D-2,3-butanediol production in Bacillus licheniformis. Biotechnol Biofuels. 2014;7:16.

28. Cheng KK, Zhao XB, Zeng J, Zhang JA. Biotechnological production of succinic acid-current state and perspectives. Biofuels Bioprod Biorefin. 2012;6:302-18.

29. Song H, Jang SH, Park JM, Lee SY. Modeling of batch fermentation kinetics for succinic acid production by Mannheimia succiniciproducens. Biochem Eng J. 2008:40:107-15.

30. Chen K, Jiang M, Wei P, Yao J, Wu H. Succinic acid production from acid hydrolysate of corn fiber by Actinobacillus succinogenes. Appl Biochem Biotechnol. 2010;160:477-85.

31. Lee PC, Lee WG, Lee SY, Chang HN. Succinic acid production with reduced by-product formation in the fermentation of Anaerobiospirillum succiniciproducens using glycerol as a carbon source. Biotechnol Bioeng. 2001:72:41-8.

32. Guo X, Cao C, Wang Y, Li C, Wu M, Chen Y, Zhang C, Pei H, Xiao D. Effect of the inactivation of lactate dehydrogenase, ethanol dehydrogenase, and phosphotransacetylase on 2,3-butanediol production in Klebsiella pneumoniae strain. Biotechnol Biofuels. 2014;7:44.

33. Larsen RA, Wilson MM, Guss AM, MetcalfWW. Genetic analysis of pigment biosynthesis in Xanthobacter autotrophicus Py2 using a new, highly efficient transposon mutagenesis system that is functional in a wide variety of bacteria. Arch Microbiol. 2002;178:193-201.

\section{Publisher's Note}

Springer Nature remains neutral with regard to jurisdictional claims in published maps and institutional affiliations.
Ready to submit your research? Choose BMC and benefit from:

- fast, convenient online submission

- thorough peer review by experienced researchers in your field

- rapid publication on acceptance

- support for research data, including large and complex data types

- gold Open Access which fosters wider collaboration and increased citations

- maximum visibility for your research: over $100 \mathrm{M}$ website views per year

At BMC, research is always in progress.

Learn more biomedcentral.com/submissions 